\title{
COMPREENSÕES DE CUIDADO E EDUCAÇÃO NA EDUCAÇÃO INFANTIL PRODUZIDAS NO ESTÁGIO SUPERVISIONADO
}

\author{
Roseli de Fátima Rech Pilonetto (UNIOESTE)* \\ https://orcid.org/0000-0001-6389-1654 \\ Marta Nörnberg (UFPel)** \\ https://orcid.org/0000-0002-9865-7056
}

\section{RESUMO}

Este artigo apresenta e discute as compreensões de cuidado e educação produzidas por acadêmicas estagiárias do terceiro ano do curso de Pedagogia de uma instituição pública. Os registros foram elaborados durante o estágio supervisionado na educação infantil, especialmente com crianças de 0 a 3 anos. As análises perpassam a produção escrita de memoriais de formação dos sujeitos investigados, os quais, ao relatarem sobre a experiência vivida com as crianças em instituições públicas de educação infantil, reestruturam suas compreensões de cuidado e educação para além dos aspectos físicos e biológicos. Evidenciase uma ampliação do sentido da docência e das práticas com bebês e crianças bem pequenas favorecidas pela articulação entre elementos práticos e teóricos construídos ao longo da formação, que são potencializados no contexto da prática docente.

Palavras-chave: Formação de professores. Cuidado e educação. Memoriais de formação.

\section{ABSTRACT}

\section{UNDERSTANDINGS OF CARE AND EDUCATION IN CHILD EDUCATION PRODUCED IN THE SUPERVISED PRACTICE}

This article presents and discusses the understandings of care and education produced by trainee scholars in the third year of the course of Education of a public institution. The records were elaborated during the supervised practice in child education, especially with children ranging from 0 to 3 years old.

Doutora em Educação pela Universidade Federal de Pelotas (UFPel). Professora Adjunta da Universidade Estadual do Oeste do Paraná (Unioeste). Membro do Grupo de Pesquisa em Educação, Crianças e Infância (Unioeste). E-mail: roselipilonetto@ hotmail.com

** Doutora em Educação pela Universidade Federal do Rio Grande do Sul (UFRGS). Professora Associada da Faculdade de Educação da Universidade Federal de Pelotas (UFPel). Membro do Grupo de Estudos sobre Aquisição da Linguagem Escrita (GEALE/UFPel). E-mail: martanornberg0@gmail.com 
The analysis show the written production of the training memorials of the investigated subjects, which, when reporting about the experience lived with the children at child education public institutions, restructure their understandings of care and education beyond the physical and biological aspects. A broadening in the sense of teaching and the practice with babies and very young children favored by the connection between practical and theoretical elements built along the training, which are enhanced in the teaching practice context, is highlighted. Keywords: Teacher training. Care and education. Training memorials.

\section{RESUMEN}

\section{COMPRENSIÓN DEL CUIDADO Y EDUCACIÓN INFANTIL PRODUCIDAS EN LA ETAPA SUPERVISADA}

Éste artículo presenta y discute las comprenciones del cuidado y educación producidas por estudiantes académicos dela tercer año dela curso de pedagogia de una institución pública. Los registros fueron elaborados durante la etapa supervisada en la educación infantil, especialmente con los niños de 0 a 3 años. Los análisis perspasan la producción escrita de los recuerdos de formación de los sujetos investigados, los cuales, informaron a cerca de la experiencia vivida con los niños en instituciones públicas de educación infantil, reestructuraron sus comprenciones del cuidado y educación más allá de los aspectos físicos y biológicos. Se evidencia un aumento del sentido de la enseñanza y de las prácticas con bebés y niños muy pequeños favorecido por las articulaciones entre elementos prácticos con teóricos construido al largo de la formación, que son potencializados en el contexto de la práctica docente.

Palabras clave: Formación de maestros. Cuidado y educación. Recuerdos de la formación.

\section{A pesquisa e seu desenho metodológico}

Estudos sobre a formação de professores para a Educação Infantil e, sobretudo, em contexto de estágio supervisionado neste nível da Educação Básica ainda são recentes. Historicamente, a formação de professores para este nível ocorria em nível médio e pós-médio ou em cursos adicionais ou de curta duração oferecidos por instituições e organizações civis, como a Organização Mundial de Educação Pré-Escolar ou, ainda, iniciativas pontuais de redes municipais de ensino (GATTI, 2010; VALDUGA, 2005). Apenas no final dos anos de 1980 algumas faculdades de educação passaram a oferecer disciplinas ou a reformular seus currículos dos cursos de Pedagogia incorporando discussões sobre a infância e a criança em idade de escolarização inicial e, muito pontualmente, sobre as crianças em idade pré-escolar (FARIA; PALHARES, 2003). Será apenas em 2002, com as Diretrizes Curriculares Nacionais para a Formação de Professores da Educação Básica (BRASIL, 2002), em decorrência da Lei no 9.694, Lei de Diretrizes e Bases da Educação Nacional (BRASIL, 1996), que a formação profissional de professores para a Educação Infantil passa a ocorrer em curso de Pedagogia. Entretanto, desde então, mesmo que estabelecido o lócus da formação de professores para a Educação Infantil em cursos de Pedagogia, vê-se a contínua necessidade de se refazer as 
práticas e as propostas de formação no interior dos cursos, especialmente favorecendo situações em que as dimensões teóricas e práticas possam ser discutidas e articuladas, bem como as concepções prévias e cristalizadas das acadêmicas em formação, sobre criança, docência e práticas de cuidado e educação, venham a ser problematizadas e transformadas.

Este artigo traz elementos que resultam de pesquisa de doutoramento (PILONETTO, 2017) desenvolvida em um curso de graduação em Pedagogia de uma instituição estadual de ensino superior pública do estado do Paraná. ${ }^{1}$ O objetivo é o de compreender as concepções de cuidado e educação de acadêmicas estagiárias em contexto de estágio supervisionado em educação infantil explicitadas em seus registros feitos ao longo da sua prática de docência com bebês e crianças bem pequenas.

Minayo (2015) caracteriza o objeto de estudo das ciências sociais como histórico, com consciência histórica, identidade entre sujeito e objeto, intrínseco e extrinsecamente ideológico e essencialmente qualitativo. Indica, ainda, que está necessariamente vinculado ao sujeito, à sociedade, às relações que ele estabelece com o outro e com o mundo, de maneira dinâmica (a história é movimento), provisória (nada está acabado ou concluído) e específica (no sentido de singularidade). Ancorado nessas posições, organizamos a moldura teórico-metodológica para realizar a análise dos registros selecionados para o estudo, observando e problematizando articulações entre contextos, sujeitos e textos.

Assim, buscamos pelas compreensões de cuidado e educação das acadêmicas estagiárias explicitadas em seus Relatos de Experiências da prática de ensino e pesquisa sob forma de estágio supervisionado, realizado no terceiro ano do curso. Inicialmente, realizamos o levantamento dos Relatos de Experiências produzidos no período de 2010 a 2014 cujo estágio foi realizado nas instituições municipais de educação infantil, o que totalizou 125 trabalhos, sendo 46 relativos à docência na creche e 79 na pré-escola. 0 Quadro 1 apresenta a distribuição dos Relatos de Experiências decorrentes de atividades de docência em cada agrupamento da Educação Infantil.

Tabela 1 - Relatos de Experiência da Prática de Ensino e Pesquisa sob Forma de Estágio Supervisionado $-2010 / 2014$

\begin{tabular}{l|c|c|c|c|c|c|c}
\hline \multicolumn{1}{c|}{ Turma } & 2010 & 2011 & 2012 & 2013 & 2014 & $\begin{array}{c}\text { Total } \\
\text { geral }\end{array}$ & $\begin{array}{c}\text { Total por Creche e } \\
\text { Pré-escola }\end{array}$ \\
\cline { 1 - 6 } Berçário - 0 a 2 anos & 6 & 4 & 6 & 1 & 4 & 21 & 46 \\
\hline Maternal I - 2 a 3 anos & 9 & 2 & 4 & 4 & 6 & 25 & 79 \\
\hline Maternal II - 3 a 4 anos & 8 & 6 & 8 & 7 & 9 & 38 & 4125 \\
\hline Pré & 12 & 6 & 9 & 10 & 4 & 41 & 125 \\
\hline Total por ano & 35 & 18 & 27 & 22 & 23 & 125 \\
\hline
\end{tabular}

Fonte: Elaborada pelas autoras deste artigo com base no Arquivo do Laboratório de Ensino e Aprendizagem de Pedagogia.

10 material empírico analisado constitui o Acervo de Materiais e Documentos Pedagógicos do Laboratório de Ensino e Aprendizagem do curso de Pedagogia da Universidade investigada. Os Relatos de Experiências analisados tiveram seu uso autorizado pelas respectivas autoras mediante assinatura de Termo de Consentimento Livre e Esclarecido.
Em seguida a esse levantamento, destacamos como material de pesquisa os 46 Relatos de Experiências das estagiárias que desenvolveram atividades com as crianças de 0 a 3 anos. Entre estes, definimos como critério analisar 
apenas os relatos que haviam sido orientados por professores efetivos do curso de Pedagogia, com mais de 5 (cinco) anos de supervisão de estágio e sem envolvimento profissional com as pesquisadoras. Assim, o material empírico de pesquisa abrangeu 11 (onze) Relatos de Experiências da prática de ensino e pesquisa sob forma de estágio supervisionado, produzidos pelas acadêmicas estagiárias sob orientação de três professores efetivos do curso, as quais desenvolveram atividades de docência com crianças de 0 a 3 anos (Berçário e Maternal I) em Centros Municipais de Educação Infantil de um município da região sudoeste do Paraná.

A escolha pelos Relatos de Experiências desenvolvidos com crianças de 0 a 3 anos decorre da posição de que há necessidade contínua de discussão e problematização das práticas de docência e das compreensões de cuidado e educação em contextos de formação de professores no curso de Pedagogia. Além disso, as pesquisas sobre a formação de professores para a docência com crianças de 0 a 3 anos são indispensáveis para pensar as dinâmicas de formação no curso de Pedagogia e, sobretudo, para ampliar a compreensão sobre os processos de docência com bebês e crianças bem pequenas, tema ainda pouco explorado no âmbito da pesquisa sobre formação de professores, sobretudo porque ainda se observa uma formação bastante generalista (GARCIA, 2019), em que aspectos relacionados às especificidades do trabalho com bebês e crianças bem pequenas ainda são pouco estudados (BARBOSA; CANCIAN; WESHENFELDER, 2018). Além disso, entendemos que na formação é preciso buscar pelas práticas teóricas da Pedagogia e, ainda, pelas dimensões didáticas e metodológicas que envolvem a docência (FABRE, 2004; MEIRIEU, 2002). Nossa posição é de que o estágio se constitui como um cenário altamente formativo e reconstrutivo das concepções teóricas em estudo num curso de formação de professores e profícuo para a transformação das noções de docência e Pedagogia em razão da interpelação das crianças.
O Relato de Experiência é composto pelos seguintes elementos textuais: introdução, relatório de observação, fundamentação teóricometodológica, planejamento diário, memorial descritivo de regência, considerações finais e referências. Para o estudo foram analisados os seguintes tópicos dos Relatos: a) fundamentação teórica - destacamos a compreensão de cuidado e educação mencionadas pelos acadêmicas estagiárias; b) planejamento diário - observamos como as acadêmicas estagiárias organizaram a rotina das crianças com foco no cuidado e educação; c) memorial descritivo de regência - identificamos as compreensões de cuidado e educação das acadêmicas estagiárias a partir dos seus relatos sobre a experiência de docência com as crianças.

Para este texto, focalizamos e discutimos as compreensões de cuidado e educação das acadêmicas estagiárias registradas em seu memorial descritivo de regência. A opção pela análise desse item dos Relatos de Experiências decorre do entendimento de que estas reflexões foram escritas em momento posterior à docência e convívio com as crianças e a instituição de educação infantil, ocasião em que as estudantes já realizaram as observações de sala de aula, da estrutura física e pedagógica; a elaboração escrita da fundamentação teórica e do planejamento de ensino; as atividades propriamente de docência na educação infantil. Em seu memorial descritivo de regência, as acadêmicas estagiárias registravam diariamente suas impressões, reflexões, angústias, problematizações, experiências feitas com as crianças.

Importa ressaltar que as atividades de estágio foram, no período investigado, realizadas em duplas de acadêmicas estagiárias. Todavia, a escrita do memorial descritivo de regência ocorreu de modo individual, pois se trata de um momento de formação pessoal e profissional, em que cada futuro professor ou professora, a partir de sua experiência singular, pode pensar e reorganizar seu processo de desenvolvimento docente. Essa posição corrobora a noção de 
que "[...] o objeto de estudo das ciências sociais possui consciência histórica. Noutras palavras, não é apenas o investigador que tem capacidade de dar sentido ao seu trabalho intelectual. Todos os seres humanos [...]dão significado a suas ações e suas construções" (MINAYO, 2015, p. 13). Nesse sentido, as compreensões das acadêmicas estagiárias escritas nos memoriais descritivos de regência evidenciam sua capacidade formativa de analisar a própria prática com as crianças e de problematizar e articular seu pensamento com os estudos realizados ao longo do curso de Pedagogia.

Os 11 Relatos de Experiências selecionados para a pesquisa foram lidos um a um. Do item memorial descritivo de regência, inicialmente, destacamos excertos que demonstravam as compreensões de cuidado e educação, criança, infância, rotina, educação infantil, formação de professores, ensino, os quais foram categorizados em: i) cuidado e educação; ii) ação pedagógica; iii) formação de professores. A seguir, elaboramos um quadro com os excertos que tratavam das compreensões de cuidado e educação escritos nos memoriais, os quais, após releituras, foram discutidos e problematizados pelas pesquisadoras, buscando evidenciar as maneiras e as noções que demonstravam como as acadêmicas estagiárias compreendiam o cuidado e a educação e, assim, modificavam suas concepções.

Com base nesse processo de análise, percebemos que a partir do contato com as crianças, ocorrido durante a regência, as acadêmicas estagiárias desestruturaram e reestruturaram suas compreensões, análises, práticas e o próprio processo formativo como professoras de educação infantil, especialmente o entendimento de docência com crianças de 0 a 3 anos. Em seus memoriais, as estagiárias trazem e discutem vários elementos da ação pedagógica com as crianças, entre eles destacam-se o brincar e o ensinar, preocupação presente na quase totalidade dos relatos analisados. A relação entre a educação e o ensino perpassa todos os memoriais, bem como a preocupação do papel do professor em ensinar algo às crianças, transmitir os conhecimentos acumulados pela humanidade. Há rápidas menções nos memoriais sobre o papel e a participação da criança na ação pedagógica, percebendo-a como sujeito ativo do processo pedagógico desenvolvido nas instituições de educação infantil, o que requer colocar a participação e as interações corporais e de linguagem como dimensões articuladoras do trabalho de formação. Por outro lado, destacamos certa ausência de reflexões sobre a pedagogia e a docência, o que indica ao campo da formação de professores aspectos importantes a serem problematizados e ainda investigados.

Discutiremos esses aspectos na sequência deste texto ao tratar das perspectivas teórico-pedagógicas que sustentam a formação no curso de Pedagogia da instituição investigada. Esses temas também são retomados na seção que apresentamos as análises dos excertos dos memoriais, os quais permitem observar a reestruturação das compreensões de cuidado e educação das acadêmicas estagiárias em razão do contato pedagógico com os bebês e as crianças bem pequenas que frequentam as instituições de educação infantil da rede pública do município em que se situa a instituição formadora.

\section{Cuidado e educação: (entre) perspectivas teórico- pedagógicas}

A partir da leitura dos memoriais descritivos de regência, percebemos que diferentes perspectivas teórico-pedagógicas constituem as escritas das acadêmicas estagiárias. Essa dimensão talvez ocorra em razão de que o colegiado do curso de Pedagogia investigado, conforme refere seu Projeto político-pedagógico,

entende que o processo educativo, em cursos de formação de educadores, é composto por várias dimensões (ontológicas, epistemológicas, antropológicas e axiológicas), presentes nas diferentes concepções de mundo, constituídas historicamente, e nas experiências educativas 
que cotidianamente são evidenciadas nas salas de aula no desenvolvimento desse processo. Nessa perspectiva, o curso busca contemplar a pluralidade e o respeito às diferentes concepções de mundo e de educação. ${ }^{2}$

Essa posição político-pedagógica oferece condições para que as acadêmicas estagiárias conheçam diferentes perspectivas de se compreender a criança, a infância, o cuidado, a educação, as instituições de educação infantil e sua rotina, bem como a formação de professores. Dentre as perspectivas, identificamos a Pedagogia Histórico-Crítica e as Pedagogias da Infância como as que aparecem em vários dos memoriais analisados. Optamos pelo uso do termo Pedagogias da Infância por este fazer referência à compreensão de pedagogia enquanto conjunto de estudos sobre teorias, práticas, saberes produzidos a partir da experiência, além de trazer elementos que auxiliam na reflexão do processo formativo do ser humano e, ainda, colocar a pedagogia como ato que se estabelece entre adultos e crianças, colocando a infância como ponto de partida e chegada da ação educativa.

Oliveira-Formosinho, Kishimoto e Pinazza (2007) contribuem com esta opção terminológica ao indicarem teorias pedagógicas que, historicamente, apresentam referências sobre a criança, a infância, o trabalho pedagógico, as instituições, o papel do professor, o processo de ensino-aprendizagem, não se limitando a uma única pedagogia da infância ou de pedagogias sobre a infância, mas evidenciando estudos que contribuem, por exemplo, para a compreensão do cuidado e educação. Além disso, a opção pelo termo Pedagogias da Infância amplia o sentido de Pedagogia para além de sua vinculação exclusiva às ciências da educação (SOËTARD, 2004). A Pedagogia está para além da relação, junção, articulação entre teoria e prática (FABRE, 2004). 0 trabalho profissional

2 Excerto retirado da página 7 da alteração do Projeto Político Pedagógico do curso de Pedagogia da instituição investigada (cujo nome será mantido em sigilo), de dezembro de 2007. do pedagogo se faz entre a teoria e a prática (MEIRIEU, 2002; SOËTARD, 2004). O pedagogo nutre-se de conhecimentos científicos, da prática em sala de aula, mas ele também produz um conhecimento que é distinto desses dois campos; o pedagogo elabora um conhecimento que só pode ser compreendido e constituído por meio da experiência da formação e da ação enquanto professor.

Destacamos, a seguir, aspectos gerais dessas perspectivas que auxiliam na análise dos memoriais descritivos de regência enquanto processo formativo, estruturador e reestruturador das compreensões de cuidado e educação das acadêmicas estagiárias em contexto de estágio supervisionado em educação infantil. Assim, as compreensões que apresentamos centramse no cuidado e educação identificados na Pedagogia Histórico-Crítica e nas Pedagogias da Infância.

A Pedagogia Histórico-Crítica, estruturada pelo filósofo Dermeval Saviani desde 1984, apoia-se no materialismo histórico dialético, de base marxista, especialmente em Marx e Engels, e também na psicologia histórico-cultural de Lev Semenovitch Vigotski, Alexander Luria, Alexei Nikolaievich Leontiev e Daniil B. Elkonin (LOMBARDI, 2013). Entende o trabalho como princípio educativo da ação pedagógica, especialmente no trabalho com os anos iniciais do ensino fundamental. Para esta perspectiva, a criança é entendida como homem, o qual é obra da educação, e a criança, com o auxílio do adulto, conhece e se apropria do que a humanidade produziu. Esse é o papel da escola, que possui uma compreensão clara e definida de educação e sociedade. A primeira tem a função de produzir no sujeito a leitura crítica do mundo, da sociedade a qual está inserido e transforma a si e a sociedade. A segunda, dividida em classes sociais, possui contradições e, pelo trabalho, o homem luta pela igualdade social. Saviani (2013, p. 250) assim define a concepção de infância pela pedagogia histórico-crítica: "o homem não nasce homem. Ele forma-se homem. Ele não nasce sabendo pro- 
duzir-se como homem. Ele necessita aprender a ser homem, precisa aprender a produzir sua própria existência". Nesse sentido, para o autor, "a produção do homem é, ao mesmo tempo, a formação do homem, isto é, um processo educativo" (SAVIANI, 2013, p. 250) e, portanto, a educação coincide com a origem do homem. Saviani (2013) discute a criança como ser humano, homem genérico, que necessita produzir para sua existência, por isso adapta a natureza às suas necessidades através do trabalho enquanto atividade intencional. 0 trabalho é considerado transformador da realidade e o homem utiliza a educação como fenômeno motor da ação transformadora para auxiliar em sua vida cotidiana e concretizar o que ele quer e precisa. Para compor esse conhecimento, o homem usa ideias, atitudes, conceitos, valores, hábitos encontrados na educação.

Para a Pedagogia Histórico-Crítica, a criança apresenta-se como um ser que está à minha frente, um indivíduo que precisa ser educado para conhecer o que a humanidade produziu nos seus aspectos econômico, político, social e cultural. Suas características são do sujeito social, capaz de aprender o que lhe é ensinado por um adulto, possibilitando que ele amplie seu conhecimento sobre o seu contexto social. A discussão de criança parte da compreensão de homem, ser humano que transforma a si e ao meio em que vive pela sua consciência e pela relação que estabelece na sociedade.

No Brasil, além de Saviani, alguns pesquisadores da Pedagogia Histórico-Crítica, pensada inicialmente para refletir sobre a educação no ensino fundamental (anos iniciais), discutem sobre a criança, a infância, a educação infantil e a formação de seus professores, além da ação pedagógica destinada às crianças de 0 a 5 anos. Entre eles, Alessandra Arce, Lígia Márcia Martins e outros colaboradores como Heloísa Helena Azevedo de Oliveira, Ana Carolina Galvão Marsiglia e Mara Regina Martins Jacomelli, que assumem a educação infantil escolarizada em uma perspectiva de crítica e emancipação humana.
Ao pensar na educação infantil, Marsiglia (2013, p. 216) relata como a criança em idade escolar precisa ser considerada, afirmando que "[...] o trabalho da criança em idade escolar depende daquilo que foi preparado em suas etapas anteriores, isto é, pela educação infantil". A autora ainda explica que [...] "é preciso criar condições para um trabalho mental ativo e, para tanto, é essencial considerar os métodos utilizados para atingir os resultados desejados como parte daquilo que estimula o aluno à realização de suas atividades" (MARSIGLIA, 2013, p. 217). Nesse sentido, a instituição de educação infantil para a Pedagogia Histórico-Crítica tem a tarefa de "ampliar o círculo de contatos com a realidade da criança" (PASQUALINI, 2013, p. 90), e ao professor compete a tarefa de transmitir a ela conhecimentos sobre o mundo, utilizando a brincadeira infantil.

A perspectiva histórico-crítica se apoia na psicologia histórico-cultural, que tem como precursores Vigotski, Elkonin, Luria e Leontiev. Com base na psicologia histórico-cultural, a criança relaciona-se com o mundo que a cerca seres humanos, objetos, natureza - por meio da mediação do adulto que apresenta o mundo, os objetos e sua utilização à criança considerando sua função social. Assim, a palavra "infantil" vincula-se à "educação", realizada na instituição escolar com a prática pedagógica e o papel do professor claros e definidos.

Azevedo (2013, p. 29), estudiosa da Pedagogia Histórico-crítica, discute a construção do conceito de infância a partir de sua constituição histórica, no Brasil e no mundo, identificando etimologicamente a palavra infância como oriunda do latim, a qual significa "incapacidade de falar" atribuída "em geral ao período que se chama de primeira infância, às vezes era vista como se estendendo até os 7 anos, que representariam a passagem para a idade da razão". A autora ainda retoma pesquisadores como Gagnebin, Platão, Santo Agostinho, Descartes, Corazza, Heywood, Ariès, Badinter para constituir o conceito de infância e, deles, destaca o trabalho de Corazza (2002) que apresenta 
três momentos históricos de compreensão do conceito de infância: 1) antes do século XVII, inexiste o conceito de infância e as crianças são consideradas como inferiores, indignas de consideração (Ariès; Demos; Hoyles; Hunt; Shorter; Stone; Thompson); 2) as relações pais/filhos são meramente formais e as necessidades das crianças não são suficientemente atendidas e observadas (tais como os estudos feitos por DeMause; Pinchbeck \& Hewitt; Plumb; Stone; Thompson); 3) século XVIII e início do XIX, a infância é ressignificada, mas as crianças ainda são brutalizadas, exploradas e submetidas a indignidades (Sears; Ariès; Hoyles; Hunt; Lyman; DeMause; Pinchbeck \& Hewitt; Plumb; Shorter; Stone; Tucker) (AZEVEDO, 2013).

Para Azevedo (2013), houve mudanças no conceito de infância no século XVII com a emergência de um sistema de educação, alteração da estrutura familiar, desenvolvimento do capitalismo, surgimento do espírito de bondade e aumento na maturidade dos pais. Nos séculos seguintes, a criança é considerada componente essencial da família e da sociedade, com direitos protegidos pelo Estado.

Azevedo (2013) ainda destaca três fases para a compreensão de infância no Brasil, assim caracterizadas: a) A fase pré 1930: uma criança que merecia os cuidados dos adultos e a igreja, principalmente através das ordens religiosas, entre eles os jesuítas, se dispunha a realizar esse papel. A função das instituições tinha como foco a guarda e os cuidados físicos, caracterizando o assistencialismo, presente até hoje no ideário de pais, da sociedade em geral e de muitos professores da área. 0 século XIX se constitui como o tempo da criação das creches que atenderam as mães trabalhadoras e os pobres. Aparecem também as instituições particulares com intenções "pedagógicas", baseadas nos jardins de infância (criança sementinha, professor jardineiro). Define-se para a criança pobre o cuidado, com atendimento de baixa qualidade, e para a criança rica, o pedagógico (escolanovismo), este último respaldado pelo momento político que o país vivia de democratização e ascensão social. Mesmo assim, não havia qualificação profissional específica para o atendimento das crianças nesse período etário; b) A fase de 1930-1980: preocupação em compensar as questões biopsicossociais das crianças e a educação deveria prepará-las para o não fracasso posterior. A concepção de "criança sementinha" e "professora jardineira" se expande em creches e pré-escolas com instituições de atendimento à criança, com a "concepção de criança como um vir a ser, algo inacabado que precisa ser moldado e preparado para o amanhã, desconsiderando-se o momento presente da criança" (AZEVEDO, 2013, p. 65); c) A fase de 1980 até a atualidade: outra visão de criança e instituição de educação infantil se constitui na sociedade brasileira. Compreendida como ser histórico, social e de direitos, a criança se insere numa cultura e sua educação vai além do cuidado assistencial, com obrigatoriedade do ingresso a partir dos quatro anos nas instituições escolares. Além disso, nesse período histórico, aumenta a preocupação com a formação dos profissionais para a educação das crianças. Ao se tratar do cuidado e educação, a lei de diretrizes e bases da educação nacional (LDB 9.394/96), segundo a autora, mantém a separação desses termos ao distinguir a educação infantil em creches e pré-escolas.

Em contrapartida, as Pedagogias da Infância compreendem a criança e a infância de maneira ampliada, as quais perpassam também as análises e reflexões das acadêmicas estagiárias nos memoriais descritivos de regência. Autores como Dahlberg, Moss e Pence (2003) indicam diferentes modos de se compreender a infância e a criança que se transpõem na maneira pedagógica de tratar a criança nas instituições de educação infantil, quando agimos diante de situações que envolvem o cuidado e a educação.

Uma criança considerada como reprodutora de conhecimento, identidade e cultura é vista como tábula rasa em que "se inscreve" conhecimentos produzidos pela humanidade, pre- 
parando-a para a vida, para a escola e demais fases da vida adulta. Individual, competitiva, consumista e flexível são algumas características dessa criança. Quando olhamos a criança como um ser inocente, a qual é corrompida pela sociedade, tendemos a protegê-la de tudo e a conduzimos para o conhecimento individual. A Psicologia é a ciência que auxilia nesse processo, contudo tendemos a psicologizar essa criança e deixamos de lado quem é a criança, em suas capacidades e potencialidades. Há ainda uma outra maneira de compreendermos a criança, que a considera em seus aspectos biológicos de desenvolvimento humano, entendendo que evolui por estágios, amadurecendo com o passar do tempo. Dessa maneira, as ações pedagógicas nas instituições de educação infantil consideram tais estágios na evolução dos aspectos físico, cognitivo e afetivo da criança. Tais compreensões de criança definem sua dependência do adulto, reafirmando um ser passivo, frágil e incapaz, características da modernidade.

No entanto, para ampliar a reflexão sobre as compreensões de cuidado e educação é necessário pensar na criança e reconceituá-la. E, para isso, Moss (2005) afirma ser necessário perguntar: "0 que são as crianças para nós?", pois, a partir daí, é possível identificar as práticas pedagógicas elaboradas pelas instituições de educação infantil, as quais nos permitem conhecer como vemos as crianças, que características elas possuem e quais são suas possibilidades de linguagem e ação.

No âmbito das Pedagogias da Infância situam-se as perspectivas construcionistas. A perspectiva construcionista "parte da premissa de que o mundo e nosso conhecimento são construídos socialmente e que todos nós, como seres humanos, somos participantes ativos desse processo, engajados no relacionamento com o outro em uma realização significativa" (MOSS, 2005, p. 237). Para os construcionistas, as crianças possuem interesses próprios, são um grupo social, têm lugar reconhecido e independente na sociedade, com direitos e obri- gações. As crianças são atores, aprendem pelo conhecimento experimental, têm voz própria, e por isso precisam ser ouvidas e consideradas com seriedade. A criança está no mundo, o influencia, é influenciada por ele, constrói significados, é coconstrutora, única, complexa e individual (DAHLBERG; MOSS; PENCE, 2003). Para este campo conceitual, "o mundo é sempre o nosso mundo, entendido e construído por nós mesmos, não isoladamente, mas como parte de uma comunidade de seres humanos" (MOSS, 2005, p. 237).

No que se refere às compreensões de cuidado e educação, estas são vistas de maneiras diferentes nas duas perspectivas teórico-pedagógicas aqui apresentadas. Saviani (2013) entende a educação como trabalho que auxilia o sujeito a produzir, direta e intencionalmente, em cada indivíduo singular, a humanidade, que vem sendo produzida histórica e coletivamente pelo conjunto dos sujeitos. Desse modo, o objeto da educação refere-se à identificação dos elementos culturais que precisam ser assimilados pelos indivíduos para que se tornem humanos, bem como à descoberta das formas mais adequadas para atingir esse objetivo. À educação cabe auxiliar o homem a distinguir o essencial do secundário, utilizando-se dos clássicos, estes considerados como o que é essencial, fundamental, diferente do conceito de antigo. Não é só na escola que se dá a educação; porém, ela é a instituição de ensino considerada fundamental para a socialização do saber sistematizado historicamente pela humanidade por meio da cultura erudita. Para a Pedagogia Histórico-Crítica, a educação escolar é responsável por garantir "a apropriação da cultura" para que assim o sujeito possa "objetivar-se e objetivar a realidade nas suas formas mais complexas" (MARTINS, 2013, p. 225). Essa defesa também ocorre para as instituições de educação infantil.

Ao pensar o cuidado, essa perspectiva teórico-pedagógica segue o percurso histórico que o determina e sua relação com o contexto econômico, político e social de uma época. 
Afirma que os cuidados físicos perpassam o sentimento de infância da criança brasileira e adentra nos locais em que as crianças são "cuidadas". Cuidar teve historicamente o sentido de proteção de um ser frágil e indefeso que necessitava ser assistido e as instituições caracterizaram-se como assistencialistas, especialmente ao atender crianças de classes sociais menos favorecidas. 0 termo pedagógico perpassa as instituições quando estas recebem crianças de classes sociais mais elevadas. Segundo Azevedo (2013), isso contribuiu para a dicotomia cuidar-educar produzida na modernidade por meio da divisão do trabalho e de classe, das necessidades sociais impostas pela evolução urbana e industrial, considerando essa dicotomia como já dada. A autora indica como solução do problema da dicotomia cuida-educar a compreensão de infância e de educação infantil na formação de professores, identificando-as nos cursos de formação e na ação dos formadores de professores.

Saviani (2013), ao considerar que o homem não nasce homem, mas se constitui no processo formativo dado pela educação, refere que os primeiros anos de vida têm papel fundamental, sendo necessário analisar as características da infância para compreendê-la e conduzir a criança a um caminho seguro, mostrando os acertos e erros construídos pela humanidade no decorrer da história. Para isso, aposta na leitura crítica das situações históricas, sociais e culturais que o homem produziu.

No âmbito das Pedagogias da Infância trazemos uma outra leitura sobre o cuidado e a educação, com base nos estudos de Guimarães (2011), que nos auxilia a pensar a criança de 0 a 3 anos como um sujeito que vem ao mundo e precisa ser envolvido, acolhido como ser humano singular que é. Sustentada pelos estudos de Foucault, principalmente com base em suas reflexões sobre as técnicas corporais e o cuidado de si, a autora ressalta a necessidade da experiência de si e do cuidado como ética, tendo o cuidado como "modo de conhecer a si, estranhar e questionar verdades autoevidentes no movimento de também conhecer o outro e cuidar do outro" (GUIMARÃES, 2011, p. 38). Nessa perspectiva, o termo cuidado é assumido ao invés do verbo cuidar, pois o cuidado da criança se faz em conjunto, isto é, entre o bebê/a criança e o adulto, o que, em nosso ponto de vista, amplia as possibilidades educativas e retira a própria Pedagogia de seu enfoque instrumental, de disciplinarização, colocando o cuidado e a própria Pedagogia na esfera da existencialidade, entendidos como encontro da criança com o adulto a partir do diálogo, da abertura e da experiência compartilhada. Atenção, reflexão, contato, emoção, atenção ao outro, ao seu corpo, à sua mente de forma integral são compreensões que consideram o sentido etimológico da palavra: "estar atento ao objeto que se cuida" com "desvelo, solicitude ou esmero" (GUIMARÃES, 2011, p. 44).

Nessa compreensão de cuidado, um componente importante para que a criança dê significado é a linguagem, pois ela interage com o mundo, com outras crianças e com o adulto, construindo sua identidade e autonomia ativamente. Considerada ativa e competente, a criança formula teorias e ideias que valem a pena serem ouvidas, questionadas e desafiadas, não precisando de permissão do adulto para que sejam elaboradas. Assim, os pais e a família continuam a ter responsabilidades pela criança pequena e compartilham com a instituição de educação infantil outros relacionamentos em que a criança convive em pequenos grupos, sejam adultos ou outras crianças, sem prejudicar seu bem-estar ou relacionamento com os pais. Essa relação insere a criança na convivência coletiva, pública, sistematizada, com objetivo definido, geralmente educativo e, também, escolar.

Delgado e Martins Filho (2013, p. 21) reuniram um grupo de autores que discutem o cuidado e a educação na primeira infância e indicam o "desafio de pensar a educação e o cuidado dos bebês e das crianças bem pequenas em contextos coletivos de Educação Infantil" que considerem "a potência de ação dos bebês". 
Para esses pesquisadores, estar em instituições de educação infantil é uma conquista das crianças, um direito a um espaço organizado para encontros com os outros, crianças e adultos. Incentivar a criatividade, o brincar, as relações com os outros e os objetos, a flexibilidade nos tempos e espaços, como ações que enriquecem culturalmente e socialmente as crianças, é entender a infância de maneira híbrida "rejeitando a naturalização da infância, o dualismo social e biológico e reconhecendo suas formações biopolíticas" (DELGADO; MARTINS FILHO, 2013, p. 24).

Assim, quando compreendemos o cuidado para além de ações mecânicas e a educação como um elemento que transcende a aquisição de conhecimentos produzidos pela humanidade, a criança também passa a ser considerada de outra maneira: ativa, potente, provocadora. As posições defendidas no âmbito das Pedagogias da Infância têm produzido proposições pedagógicas que colocam a criança como agente social ativo, em interação com o adulto, apostando num sujeito histórico, rico de potencialidades, e a reconhecem como construtora de conhecimentos na vivência com outras crianças e com adultos, e com o próprio mundo.

As noções aportadas por estas duas perspectivas foram identificadas na análise dos excertos dos memoriais descritivos de regência. Inicialmente, observamos a compreensão de criança como sujeito que precisa ser preparada para o futuro com a mediação do adulto que ensina os conhecimentos produzidos pela humanidade. As instituições de educação infantil teriam, segundo as acadêmicas estagiárias, a função educativa e o papel de realizar essa transmissão às crianças, cabendo ao professor a direção dessa ação pedagógica. Entretanto, a partir do contato pedagógico com as crianças de 0 a 3 anos, percebemos uma reestruturação das compreensões de cuidado e educação, sendo muitas delas problematizadas e discutidas com base em elementos que se aproximam das noções propostas pelas pedagogias da infância.
A seguir, mostramos como as acadêmicas estagiárias analisam suas ações durante a regência do estágio curricular e, no contato com as crianças, mostram pistas que nos permitem observar como reestruturam suas compreensões de cuidado e educação.

\section{Reestruturando compreensões de cuidado e educação no contato com as crianças}

As perspectivas teórico-pedagógicas, descritas acima, identificadas como base nas reflexões e análises que as acadêmicas estagiárias registram em seus memoriais descritivos de regência, demonstram as estruturações, desestruturações e reestruturações conceituais por elas realizadas por meio do contato com as crianças, especialmente nas compreensões de cuidado e educação. Em um dos memoriais, localizamos a seguinte afirmação:

As atividades estavam voltadas para a troca de roupas, fraldas, alimentação e higienização. Estes afazeres nos restringiam quanto ao tempo das atividades lúdicas que havíamos planejado. Mas, no decorrer da regência, compreendemos que [....] toda ação desenvolvida deveria ser pensada para que fosse significativa, tanto para o educador, quanto para a criança. Um diálogo durante a troca de fraldas é exemplo disso. (RE11, 2014). ${ }^{3}$

Essa reflexão demonstra como o contato com as crianças desestrutura compreensões trazidas pelas acadêmicas estagiárias durante a regência do estágio supervisionado, mobilizando e ao mesmo tempo perturbando o que já se sabe, reorganizando ideias, compreensões e ações. Dahlberg, Moss e Pence (2003, p. 109) sugerem que precisamos "atentar aos movimentos infantis, compreendendo as narrativas gestuais e orais das crianças, tomando-as como 'conteúdos' para as situações de construção

3 Os Relatos de Experiência foram numerados de RE1 a RE11, a fim de manter em sigilo os nomes das estudantes de Pedagogia. 
do conhecimento". Nesse sentido, a docência requer agir como construtora de espaços relacionais, o que pede pela atuação em parceria e pela criação de condições que favoreçam a interlocução das crianças com o mundo, entre si, com elas próprias, com suas famílias.

Perceber potências e manifestações das crianças através de ações de contato se constituem em práticas pedagógicas capazes de produzir na criança seu processo de individualização, de autocontrole ou autonomia com relação às suas escolhas individuais ou coletivas, além da responsabilidade de si e de suas possibilidades. Proporcionar espaços e momentos que mobilizem o conhecimento crítico, reflexivo e criativo é uma atividade da pedagogia. Diálogo, conversa, negociação, encontro, confrontação, conflito são processos de relacionamento que constroem a individualidade da criança e estão na base das práticas teóricas da Pedagogia (MEIRIEU, 2002).

Assim, apostamos num trabalho pedagógico na formação de professores com base em encontros, em relacionamentos, na comunicação, no ouvir o mundo da criança presente nas instituições de educação infantil. Ao futuro professor e também aos formadores de professores é necessário perguntar, constantemente, quem é a criança, qual sua potencialidade, do que ela é capaz, como ela se coloca no mundo, o que faz e como o faz.

Em outro memorial descritivo de regência, localizamos a seguinte reflexão sobre os cuidados corporais, especialmente nos momentos de higiene e alimentação:

A parte da troca foi uma grande aprendizagem, pois nunca tinha trocado nenhuma fralda. Enquanto os trocava, conversava com eles, trocávamos sorrisos e aprendíamos juntos. 0 mesmo ocorreu na hora de arrumar as mamadeiras, acertar a temperatura do leite para não correr o risco de queimá-los. A responsabilidade é enorme [...] O bebê, no seu primeiro ano de vida, está totalmente dependente do adulto, e é ele quem determina seus hábitos, pois é o adulto quem apresenta o mundo no qual a criança irá viver. (RE9, 2012).
As Pedagogias da Infância consideram a criança que chega a este mundo como um ser ativo, interativo, coconstrutor, sujeito de potencialidades, e o adulto é quem a acolhe e apresenta o mundo como ele é, para que ela, a criança, sinta-se parte dele e capaz de nele mobilizar ações que melhorem sua (con) vivência nele e com os que fazem parte de sua vida. Nesse sentido, o trabalho pedagógico e a formação de professores são importantes, pois cuidam de e educam uma criança constituída e constituidora desse mundo. Cuidam para pensar, mexer, provocar, refletir sobre si, o outro e o mundo que a constitui. Educam para conhecer o que se produziu, o que mobilizou o ser humano a estar nesse mundo e a fazê-lo melhor.

Bárcena e Mélich (2000, p. 15) nos instigam a uma prática pedagógica baseada numa pedagogia da radical novidade, pois, para os autores, "nuestra propuesta pedagógica, la relación con el otro no es una relación contractual o negociada, no es una relación de dominación ni de poder, sino de acogimiento. Es una relación ética basada en una nueva idea de responsabilidad". É ainda, segundo os pensadores, uma pedagogia que reconhece que a hospitalidade é anterior à propriedade porque quem pretender acolher o outro já foi acolhido por um mundo em que juntos habitam. Essa posição conceitual alinha-se com a noção de natalidade, em Arendt (2011), para quem a tarefa da educação é a de acolher e mostrar ao que chega o que é o mundo e, assim, por meio da educação, criar espaço para que este, a criança que nasce, possa fazer seus inícios e reinventar o próprio mundo.

A pedagogia é compreendida aqui como criação e não como produção; como uma possibilidade poética de dar ao sujeito condições de alimentar suas utopias. Trata-se de uma educação como um acontecimento ético que permite não só que conceitos considerados cientificamente comprovados sejam elementos de formação, mas que a vida e as relações com o mundo sejam colocadas no conjunto das nossas preocupações e reflexões. 
Ao apostar numa prática pedagógica que transgrida o discurso dominante de educação que coloca a criança apenas como aluno, numa relação em que somente o professor possui o conhecimento necessário para o desenvolvimento integral da criança, elabora-se um pensamento pedagógico que valoriza a criança, o pedagogo, a cultura, o conhecimento de si e do mundo, a identidade, os pais e os gestores. Sair do conforto de um trabalho pedagógico linear e colocar em evidência a relação da criança com o adulto e com outras crianças é o que possibilita uma perspectiva construcionista social.

A pedagogia, aliada a outras ciências, se tornou um aspecto central na constituição de uma instituição dedicada à educação infantil, quando permite compreender como se vê a criança, as relações de poder instituídas entre adultos e crianças, as possibilidades de ação pedagógica na instituição. Discutir com o outro sobre as próprias crenças e entendimentos resulta na problematização das práticas e daquilo que é tido como verdade, além de oportunizar que outras formas de experimentar sejam criadas e vivenciadas nas instituições. Essa é a aposta em uma perspectiva de ação pedagógica construída por sujeitos que fazem parte de uma comunidade, habitam o mundo com suas experiências e nele criam possibilidades coletivas de crescimento humano, individual e coletivo. Portanto, no âmbito da perspectiva construcionista social, a implicação estruturante é de que a criança e o pedagogo são vistos como coconstrutores do seu próprio conhecimento, do seu ambiente e de si próprios, pois "[a] aprendizagem não pode ser vista como um ato cognitivo individual, algo que está ocorrendo na mente da criança, mas como um ato cooperativo e comunicativo" (DAHLBERG; MOSS; PENCE, 2003, p. 176).

No diálogo com o mundo, o conhecimento se cria e se recria. Contudo, no cotidiano da formação temos sido habituados a receber orientações de como fazer e de encontrar "culpados" quando a aprendizagem das crianças não está a contento. Contudo, quando registramos, refletimos, dialogamos sobre nossas práticas pedagógicas, abrimos um espaço para problematizar e assim damos luz às próprias limitações, inseguranças e não-saberes. Essa exposição requer apoio intelectual e coletivo para encontrar possibilidades, fazer análises e agir.

Na formação inicial de professores encontramos evidências desse tipo de situação, principalmente quando as acadêmicas estagiárias estão em contexto de estágio supervisionado. Olhar o que o outro - a professora - faz ou deixou de fazer não pode ser a premissa da formação, mas pode ser mobilizador de reflexões sobre a prática, sobre as compreensões constituídas em sua formação. 0 contato com as crianças, especialmente as de 0 a 3 anos, nas instituições de educação infantil, tem se constituído um local de provocações sobre a compreensão de criança, infância, cuidado e educação; sobre que professor se quer ser diante da potencialidade que as crianças possuem e demonstram no cotidiano dos estágios supervisionados; sobre qual docência e pedagogia são capazes de resguardar a capacidade das crianças fazerem seus inícios e estabelecerem suas interações culturais, sejam elas no âmbito cognitivo, social, emocional ou laboral.

No estágio supervisionado, a experiência, no sentido dado por Larrosa (2004, 2015), desestrutura as compreensões pré-existentes das acadêmicas estagiárias e as amplia a partir do contato e das manifestações das crianças de 0 a 3 anos. Entre os memoriais analisados, localizamos posições que mostram este deslocamento e ampliação de sentidos sobre a criança e as práticas de docência:

E superamos a ideia de que as crianças não conseguem fazer as atividades, de que não são capazes; muito pelo contrário, elas nos surpreendem. [...] A atividade da bandinha, a qual eu confeccionei de garrafas peti com sementes dentro para fazer barulho, foi impressionante como eles gostaram e balançavam para ouvir o barulho e cantamos juntos, alguns com duas garrafas (RE9, 2012). 
Os memoriais descritivos de regência expressam a singularidade da convivência com as crianças, revelando uma compreensão de cuidado e educação que foi se desestruturando e se mostrando imbricada pelas ideias de criança e infância, instituições de educação infantil, formação de professores e ação pedagógica. 0 excerto abaixo demonstra essa relação:

Devido ao fato dos pequenos terem em média um e dois anos, acredito ter sido um desafio trabalhar com essa turma, pois as crianças necessitavam, além da educação, o cuidado, que se manifestava por meio de trocas de fraldas, banhos, alimentação e, principalmente, o cuidado pela integridade física das crianças, por consequência de brigas e da falta de coordenação motora de alguns, que ainda não estavam caminhando com segurança. [...] Maior parte do 'medo' de trabalhar com crianças pequenas na faixa etária de um ano a um ano e quatro meses pode-se dizer que foi devido a conhecer a importância que é ensinar estes, bem como a responsabilidade de cuidar da higiene, alimentação, evitar brigas e se as atividades seriam correspondidas e se eu daria conta de todas as funções de um professor com competência. [...] Juntamente com o ensino, está articulado o cuidado do corpo das crianças, o qual em nossa regência tomou muito tempo. (RE1, 2010).

A escrita dos memoriais revela a presença do cuidado nos aspectos físicos (higiene, alimentação, sono), mas também mostra que quando as acadêmicas estagiárias criaram espaço de diálogo entre elas e as crianças, relações de confiança, aprendizagem e respeito se estabeleceram. É explícita a compreensão das acadêmicas estagiárias de que é preciso ensinar as crianças, principalmente por meio de atividades por elas organizadas, na ânsia de mostrarem sua competência em serem professoras, mas as crianças, na sua potência e vivacidade, demonstram às acadêmicas estagiárias que se pode aprender juntos quando se escuta e se vê o outro, a criança, em suas diferentes manifestações. 0 próximo excerto ilustra esse movimento:

Em relação às atividades de higiene realizadas no banheiro, a [nome da orientadora do estágio] nunca esteve presente e este era um dos meus momentos preferidos porque havia sempre algumas que nos estranhavam, choravam, e para acalmá-las eu contava histórias, cantava, conversava com elas e assim estes procedimentos acabavam sendo prazerosos. [...] As crianças com a qual desenvolvemos nossa proposta de trabalho eram muito pequenas, de um a dois anos, e a maioria delas utilizava fralda, então os cuidados de higiene eram intensos. No entanto, procuramos realizar estas tarefas inserindo músicas, histórias e diálogos dos conteúdos que estávamos trabalhando e assim foi possível estabelecer uma relação educativa e com respeito aos indivíduos com quem estávamos trabalhando. Dessa forma, estas atividades não eram meramente mecânicas, mas sim prazerosas porque nos possibilitou realizar um trabalho e obter um conhecimento mais individual a respeito de cada criança. (RE3, 2010).

Quando se trata da ação pedagógica com os bebês, as acadêmicas estagiárias apontam a dificuldade em ensinar crianças da turma do berçário, especialmente durante a condução de atividades previamente planejadas. A presença do ensinar na educação infantil identifica-se com as ideias apresentadas por Martins (2009) e que sustentam a principal base teórico-pedagógica presente no curso de Pedagogia investigado, a Pedagogia HistóricoCrítica. Percebemos que a presença dos bebês e sua demonstração de desejos, vontades, necessidades colocam as acadêmicas estagiárias em situação de desconforto e as fazem priorizar as crianças. Abandona-se a prescrição pedagógica e faz-se pedagogia. Reconhecer que o bebê é capaz de aprender e que sua presença no berçário é ativa permite condições para que possamos recriar espaços de acolhimento em que o bebê se identifique com o aconchego e o afeto que muitas vezes ficam restritos ao universo familiar. O berçário é um espaço que ainda precisa ser explorado pelas acadêmicas estagiárias como espaço e tempo de escuta e partilha entre criança e adultos em atos de cuidado e educação. No caso dos memoriais analisados, observamos que essa estrutura de compreensão de cuidado e educação é grada- 
tivamente desestruturada pela presença/ação da criança. Esse movimento de reestruturação da compreensão do cuidado e educação pode ser acompanhada no excerto abaixo:

Cuidar e educar é ter uma ação pedagógica consciente, estabelecendo uma visão integrada do desenvolvimento da criança com base em concepções que respeitem a diversidade, o momento e a realidade peculiares à infância. [...] implica reconhecer que o desenvolvimento, a construção dos saberes, a constituição do ser não ocorre em momentos compartimentados. A criança é um ser completo [...] significa compreender que o espaço/tempo em que a criança vive exige seu esforço particular e a mediação dos adultos como forma de proporcionar ambientes que estimulem a curiosidade com consciência e responsabilidade. [...] 0 problema da separação entre cuidado e educação é uma decorrência da tentativa de superação do caráter assistencial substituindo-o pelo caráter pedagógico, o que também é amplamente discutido. [...] Cuidar e educar sempre estiveram associados e a cisão entre tais processos não está na sua pretensa desarticulação, mas em como são vistos os sujeitos infantis, como contribuintes da sociedade com propósitos diferenciados. [...] cuidar e educar são indissociáveis, pois a criança deve ser considerada em suas particularidades, o educador deverá ter uma concepção de criança, de quem é a criança, ter consciência de estar sempre refletindo sua prática pedagógica. (RE8, 2012).

Embora as ideias ainda mesclem elementos e termos que encontram guarida na Pedagogia Histórico-Crítica, especialmente quando evidenciam a indissociabilidade entre cuidar e educar, é possível perceber que as reflexões de cuidado e educação apresentadas trazem elementos para além do atendimento físico e biológico da criança, especialmente quando referem a singularidade do sujeito de cuidado e educação, que se torna ator e construtor de seu aprendizado ao explorar e experimentar o mundo, constituída de desejos, sentidos, sentimentos, expectativas para com o mundo, reconhecendo o bebê como um agente social que se relaciona, capaz de descobrir-se com seu próprio corpo e pelo contato com o outro. Essas compreensões manifestadas no RE8 de- monstram que, a partir da experiência com as crianças, diferentes reflexões são provocadas, distintas das que as acadêmicas estagiárias possuíam antes desse contato.

Ao analisar longitudinalmente as escritas feitas nos 11 memoriais descritivos de regência, é possível observar que as ações voltadas ao cuidado são compreendidas pelas acadêmicas estagiárias, no início de sua formação, como "perdas de tempo"; mas, à medida em que se colocam na presença da criança, e são por elas interpeladas, suas posições vão se reestruturando. Nesse sentido, é por meio da relação criança-adulto que a própria formação para a docência na educação infantil se amplia e se modifica. Uma das razões que localizamos com base na análise feita é de que as crianças demonstram a importância desses momentos quando se manifestam com risos, comentários, falas, gestos e são tocadas, ouvidas, observadas pelas acadêmicas estagiárias. É por meio desses atos de pedagogia que a docência vai se configurando como atividade entre humanos. Além desses aspectos, a análise também mostra que registrar nossas experiências com as crianças mobiliza reflexões sobre nossa ação, sobre o que sabemos e, ainda, podemos compreender e modificar nossas formas de pensar e agir enquanto adultos e, sobretudo, como docentes.

Outro elemento importante refere-se às relações que se estabelecem entre as compreensões de criança, infância, formação de professores, ação pedagógica e instituições expressas pelas acadêmicas estagiárias em seus memoriais. Nessa relação, é interessante ver como as acadêmicas estagiárias desestruturam suas compreensões de cuidado e educação e, igualmente, seu processo de formação profissional. 0 excerto abaixo exemplifica isso:

Começamos a tarde deixando alguns colchões no chão, que aproveitamos para contar histórias e brincar de rolar conforme as crianças acordavam, e no fim foi uma bagunça e tanto. [...] Não éramos apenas nós que estávamos mais soltas com as crianças, mas elas também conversavam entre si e com nós de uma forma mais clara porque demos a elas espaço para manifestar 
suas opiniões a respeito das professoras estagiárias, das brincadeiras, e na maioria das vezes a resposta veio em um gesto de carinho e afeto. (RE3, 2010).

0 excerto acima revela como a presença, o contato, a participação da criança desestrutura e reestrutura as ideias das acadêmicas estagiárias quando a criança é vista como "rica", que não precisa de permissão do adulto para participar e aprender, como ativa e competente (DAHLBERG; MOSS; PENCE, 2003). As situações descritas nos memoriais demonstram, ainda, situações de cuidado "na perspectiva de atenção ao outro" (GUIMARÃES, 2011, p. 54) não apenas em momentos de higiene, mas na observação e escuta da criança, em sua manifestação gestual, corporal, verbal.

Durante o estágio de docência na educação infantil, o observar a criança permitiu às acadêmicas estagiárias ouvi-la, mesmo quando esta não falava, algo fundamental na relação adulto-criança. A escuta do outro - a criança - e a experimentação na educação infantil permitem que a criança aprenda, se desenvolva e interaja. Essa ideia mostra "que as construções da infância e das crianças são produtos da prática; em outras palavras, o trabalho pedagógico é o produto de quem pensamos que a criança pequena seja" (DAHLBERG; MOSS; PENCE, 2003, p. 75). Com esse enfoque, o trabalho da professora de educação infantil demanda ouvir ideias, teorias e hipóteses formuladas pelas crianças, respeitando-as, atendendo com zelo suas necessidades e particularidades. Ser docente significa criar espaço relacional para que a criança construa suas alternativas de leitura e compreensão do mundo.

\section{Comentários finais}

Com base no trabalho de pesquisa realizado, ressaltamos a importância da escrita do memorial descritivo de regência como uma estratégia metodológica de análise da própria prática docente, que possui alto valor formativo, pois permite a reflexão sobre elementos que constituem a formação, o trabalho docente e os meandros da prática pedagógica, os quais, muitas vezes, os cursos de formação inicial nem sempre conseguem explicitar ao longo de suas dinâmicas e propostas. No caso deste estudo, esta metodologia se apresentou como uma possibilidade que permitiu também observar modificações e reestruturações dos conceitos de cuidado e educação dos sujeitos diante da ponderação de sua formação antes do contato com as crianças e após este.

A desestruturação de compreensões das acadêmicas estagiárias evidenciadas na escrita dos memoriais implica na formação, pois colocou em tensão razões da escolha de ser professora, bem como foi mostrando os limites, as possibilidades, os problemas e as alegrias que o estar-junto com as crianças viabiliza. A presença corresponsável do professor de educação infantil requer sua atenção à criança e ao que é inerente a sua profissão, o conhecimento teórico-prático e a reflexão sobre seu trabalho. As acadêmicas estagiárias entendem que é necessária a prática permanente de observação, de registro e de reflexão da ação pedagógica com as crianças. Essas ações permitem significativas mudanças no trabalho com as crianças e na sua valorização enquanto ser em potencial.

As acadêmicas estagiárias observaram que nas instituições de educação infantil o cuidado do corpo (alimentação, higiene e sono) tem prioridade e esse fato provoca o curso de formação de professores a pensar sobre quais discussões estão sendo realizadas quanto à criança, à infância, ao cuidado, à educação e à própria formação de professores para a educação infantil. Certamente, a formação de professores, especialmente no curso de Pedagogia, precisa investir em estudos que se debruçam sobre esses elementos, ouvindo o que as acadêmicas estagiárias trazem do desenvolvimento das atividades vinculadas ao estágio supervisionado curricular.

O que está claro, com base na escrita dos memoriais descritivos de regência, é o fato de que ser professora de educação infantil requer 
uma formação teórico-prática sólida e consistente sobre a criança e seu desenvolvimento; sobre o papel do professor e das instituições de primeira infância. 0 que também percebemos ao analisar os memoriais é que a experiência com a criança proporciona outro olhar sobre ela, permitindo que a acadêmica estagiária, futura professora, reconheça as suas potencialidades e os seus limites. Assim, a escrita dos memoriais ao longo da experiência de docência com as crianças tem produzido um movimento reflexivo no âmbito da formação de professores de educação infantil no curso de Pedagogia da instituição investigada. Esse movimento provoca reflexões e análises sobre as teorias pedagógicas estudadas ao longo do curso, mobilizadas principalmente em razão do contato com as crianças que frequentam as instituições de educação infantil, reestruturando as compreensões de cuidado e educação das futuras professoras.

\section{REFERÊNCIAS}

ARENDT, Hannah. A crise na educação. In: ARENDT, Hannah. Entre o passado e o futuro. 7. ed. São Paulo: Perspectiva, 2011. p. 221-247.

AZEVEDO, Heloisa Helena Oliveira de. Educação infantil e formação de professores: para além da separação cuidar-educar. São Paulo: Editora UNESP, 2013.

BARBOSA, Maria Carmen Silveira; CANCIAN, Viviane Ache; WESHENFELDER, Noeli Valentina. Pedagogo generalista - professor de educação infantil: implicações e desafios da formação. Revista da FAEEBA - Educação e Contemporaneidade, Salvador, v. 27, n. 51, p. 45-67, jan./abr. 2018.

BÁRCENA, Fernando; MÈLICH, Joan-Carles. Introducción uma pedagogia de La radical novedad. In: BÁRCENA, Fernando; MÈLICH, Joan-Carles. La educación como acontecimiento ético: Natalidad, narración y hospitalidad. Barcelona: Paidós, 2000. p. 11-33.

BRASIL. Ministério da Educação. Lei n. 9.394, de 20 de dezembro de 1996. Estabelece as Diretrizes e Bases da Educação Nacional. Diário Oficial da União: seção 1, Brasília, DF, ano 134, n. 248, p. 27834-27841, 23 dez. 1996.
BRASIL. Resolução CNE/CP 1/2002. Diário Oficial da União: seção 1, Brasília, DF, ano 139, p. 31, 9 abr. 2002. Republicada por ter saído com incorreção do original no DOU de 4 de março de 2002.

CORAZZA, Sandra Mara. Infância \& educação - Era uma vez... quer que conte outra vez? Petrópolis, RJ: Vozes, 2002.

DAHLBERG, Gunilla; MOSS, Peter; PENCE, Alan. Qualidade na educação da primeira infância: perspectivas pós-modernas. Porto Alegre: Artmed, 2003.

DELGADO, Ana Cristina Coll; MARTINS FILHO, Altino José. Apresentação do dossiê "Bebês e crianças bem pequenas em contextos coletivos de educação". Pro-Posições, v. 24, n. 3, p. 21-30, 2013.

FABRE, Michel. Existem saberes pedagógicos? In: HOUSSAYE, Jean. et al (org.). Manifesto a favor dos pedagogos. Porto Alegre: Artmed, 2004. p. 97-120.

FARIA, Ana Lúcia Goulart de; PALHARES, Marina Silveira (org.). Educação infantil pós-LDB: rumos e desafíos. 4. ed. São Paulo: Autores Associados, 2003.

GARCIA, M. M. A. Quimeras do curso de pedagogia: a formação para a docência na educação infantil e nos anos iniciais. Revista Práxis Educacional, Vitória da Conquista, BA, v. 15, n. 33, p. 91-117, jul./set. 2019.

GATTI, Bernardete Angelina. Formação de professores no Brasil: características e problemas. Educação \& Sociedade, v. 31, n. 113, p. 1355-1379, dez. 2010.

GUIMARÃES, Daniela. Relações entre bebês e adultos na creche: o cuidado como ética. São Paulo: Cortez, 2011.

LARROSA, Jorge. Notas sobre a experiência e o saber da experiência. In: GERALDI, Corinta M. G.; RIOLFI, Claudia Rosa; GARCIA, Maria de F. (org.). Escola viva: elementos para a construção de uma educação de qualidade social. Campinas, SP: Mercado das Letras, 2004. p. 113-132.

LARROSA, Jorge. Tremores: escritos sobre experiência. Belo Horizonte: Autêntica, 2015.

LOMBARDI, José Claudinei. Notas sobre a educação da infância numa perspectiva marxista. In: MARSIGLIA, Ana Carolina Glavão (org.). Infância e pedagogia histórico-crítica. São Paulo: Autores Associados, 2013. p. 7-16.

MARSIGLIA. Ana Carolina Galvão. Contribuições 
para os fundamentos teóricos da prática pedagógica histórico-crítica. In: MARSIGLIA, Ana Carolina Galvão (org.). Infância e pedagogia históricocrítica. São Paulo: Autores Associados, 2013. p. 213-246.

MARTINS, Ligia Márcia. O ensino e o desenvolvimento infantil de zero a três anos. In: ARCE, Alessandra; MARTINS, Lígia Márcia (org.). Ensinando aos pequenos de 0 a 3 anos. Campinas, SP: Alinea, 2009. p. 93-122.

MARTINS, Lígia Márcia. O papel da educação escolar na formação de conceitos. In: MARSIGLIA, Ana Carolina Galvão (org.). Infância e pedagogia histórico-crítica. São Paulo: Autores Associados, 2013. p. 117- 144.

MEIRIEU, Philippe. A pedagogia entre o dizer e o fazer. A coragem de começar. Trad. Fátima Murad. Porto Alegre: Artmed, 2002.

MINAYO, Maria Cecília de Souza (org.). Pesquisa social: teoria, método e criatividade. 34. ed. Rio de Janeiro: Vozes, 2015.

MOSS, Peter. Reconceitualizando a infância: crianças, instituições e profissionais. In: MACHADO, Maria Lúcia de A. (org.) Encontros e desencontros em educação infantil. 2. ed. São Paulo: Cortez, 2005. p. 235-248.

OLIVEIRA-FORMOSINHO, Julia; KISHIMOTO, Tisuko Morchida; PINAZZA, Monica Appezzato (org.). Pe- dagogia(s) da infância: dialogando com o passado, construindo o futuro. Porto Alegre: Artmed, 2007.

PASQUALINI, Juliana Campregher. Periodização do desenvolvimento psíquico à luz da escola de Vogotski: a teoria histórico-cultural do desenvolvimento infantil e suas implicações pedagógicas. In: MARSIGLIA, Ana Carolina Galvão (org.). Infância e pedagogia histórico-crítica. São Paulo: Autores Associados, 2013. p. 71-98.

PILONETTO, Roseli de Fátima Rech. Cuidado e educação: compreensões construídas em contexto de estágio supervisionado em Educação Infantil. 2017. 258f. Tese (Doutorado em Educação) - Faculdade de Educação, Universidade Federal de Pelotas (UFPel), Pelotas, RS, 2017.

SAVIANI, Dermeval. Infância e pedagogia históricocrítica. In: MARSIGLIA, Ana Carolina Galvão (org.). Infância e pedagogia histórico-crítica. São Paulo: Autores Associados, 2013. p. 247-280.

SÖETARD, M. Ciência(s) da educação ou sentido da educação? A saída pedagógica. In: HOUSSAYE, Jean et al (org.). Manifesto a favor dos pedagogos. Porto Alegre: Artmed, 2004. p. 47-69.

VALDUGA, Denise Ariana Francisco. Processo de formação docente das educadoras leigas de creches comunitárias. 2005. $239 \mathrm{f}$. Tese (Doutorado em Educação) - Faculdade de Educação, Universidade Federal do Rio Grande do Sul (UFRGS), Porto Alegre, 2005. 